\title{
Mississippian chondrichthyan fishes from the area of Krzeszowice, southern Poland
}

Michał Ginter and Michał Złotnik

Acta Palaeontologica Polonica 64 (3), 2019: 549-564 doi:https://doi.org/10.4202/app.00619.2019

Two new assemblages of Mississippian pelagic chondrichthyan microremains were recovered from the pelagic limestone of the area of Krzeszowice, NW of Kraków, Poland. The older assemblage represents the upper Tournaisian of Czatkowice Quarry and the younger one the upper Viséan of the Czernka stream valley at Czerna. The teeth of symmoriiform Falcatidae are the major component of both collections. A comparison of the taxonomic composition of the assemblage from Czerna (with the falcatids and Thrinacodus as the major components) to the previously published materials from the Holy Cross Mountains (Poland), Muhua (southern China), and Grand Canyon (Northern Arizona, USA) revealed the closest similarity to the first of these, probably deposited in a deeper water environment, relatively far from submarine carbonate platforms. A short review of Mississippian falcatids shows that the late Viséan-Serpukhovian period was the time of the greatest diversity of this group.

Key words: Chondrichthyes, Falcatidae, teeth, Carboniferous, Tournaisian, Viséan, Poland, Kraków Upland.

Michał Ginter [m.ginter@uw.edu.pl] and Michał Z łotnik [m.zlotnik@uw.edu.pl], Faculty of Geology, University of Warsaw, Żwirki i Wigury 93, 02-089 Warszawa, Poland.

This is an open-access article distributed under the terms of the Creative Commons Attribution License (for details please see creativecommons.org), which permits unrestricted use, distribution, and reproduction in any medium, provided the original author and source are credited. 
